\title{
Using of CelluBOR on Noise Enclosures
}

\author{
Hüseyin $\mathrm{DAL}^{*}$
}

\begin{abstract}
An investigation was conducted into the reduction of the noise caused by machines used in the manufacturing industry. Four noise cabin models, outfitted with two types of insulation-materials for the cabin walls - Styrofoam (Expander Polystyrene - EPS) and CelluBOR - were constructed. For each cabin model, a high-level noise source was employed, in accordance with operation conditions, to perform noise measurement and frequency analysis. The results indicated that CelluBOR was an effective material for ensuring noise insulation
\end{abstract}

Keywords - CelluBOR, Noise enclosure, Noise Isolation

\section{Introduction}

Many countries apply various measures for protecting their workers from high-level noise [1,2]. Numerous studies on this issue have been conducted, including the hearing health problems involving children born from pregnant women subject to occupational noise [3], the effect of noise in cement plants on human health [4], the noise that workers in civil aircraft maintenance are subjected to [5], the noise-induced hearing loss in steel industry workers and the relationship between hearing loss and lead level in the blood [6], and the impact noise has on the cardiovascular system [7].

Covering the noise source is one of the methods used for noise control. Research focusing on different methods of concealing the noise source includes studies by Pääkkönen and Tikkanen [8], who constructed a low-frequency noise cabin with a sound frequency of $0.2-320 \mathrm{~Hz}$; Locati et al. [9], who designed a special noise cabin; Dupont and Galland [10], who designed an active absorber for a noise cabin; Li [11], who used a two-walled acoustic cabin, where voids served as resonators in the walls; Tarabini and Roure [12], who modelled the parameters affecting the active noise control on a cabin wall; and finally, Yu and Cheng [13], who investigated the optimization of the location of T-shaped acoustic resonators.

In this study, the effects of CelluBOR use on the noise reduction in designed noise cabins were investigated by measuring and analysing noise levels. Another sound insulation material-Styrofoam — which has the same density as CelluBOR, was used for comparison. Results indicated that CelluBOR could be used effectively as a sound insulation material.

Hüseyin DAL ${ }^{*}$

Faculty of Engineering / University of Sakarya Turkey

Ömer K. MORGÜL

Faculty of Engineering / University of Sakarya Turkey
Ömer K. MORGÜL

\section{Cabin Models and Noise Measurements}

CelluBOR is composed of boric acid, borax penta hydrate, cellulose, waste paper and sodium silicate neutral Fig. 1.

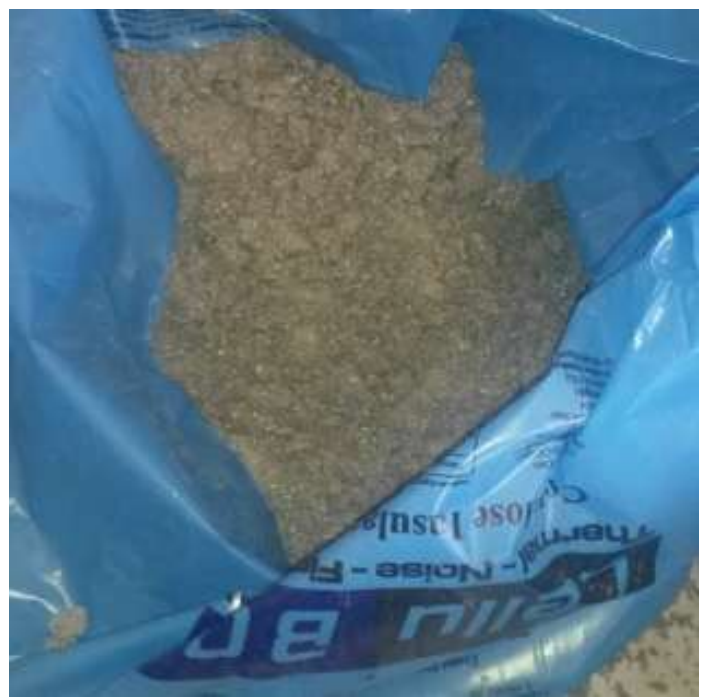

Figure 1. CelluBOR material in a sack

It is a mineral fibre based environmentally and friendly materials. Actually CelluBOR is an ecological and economical thermal insulation material to be used on ceilings, attics, floors and wall structures. Run through a blowing machine, loose fill can be installed in a wall or on a surface through access holes after the interior finish has gone up, or installed into a netting system or reinforced poly-barrier retaining membrane Fig. 2. Its density ranges between 15 and $150 \mathrm{~kg} / \mathrm{m}^{3}$ [14].

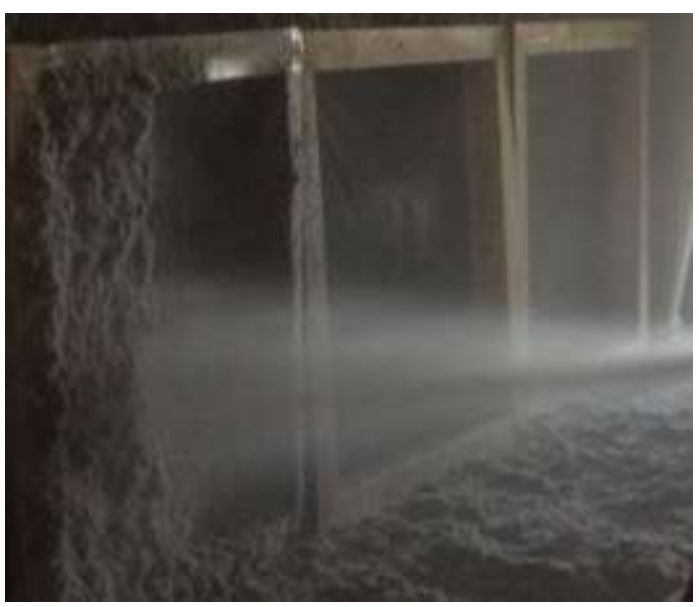

Figure 2. CelluBOR material in a sack 
Proc. of the Fourth Intl. Conf. Advances in Civil, Structural and Mechanical Engineering- CSM 2016

Copyright (C) Institute of Research Engineers and Doctors, USA .All rights reserved.

ISBN: 978-1-63248-093-4 doi: 10.15224/ 978-1-63248-093-4-34

Table 1. Cabin model parameters

Two 120x120x120 cm CelluBOR and Styrofoam cabins, each of whose wall thicknesses were 5 and $10 \mathrm{~cm}$, were constructed, as shown in Fig. 3, Fig. 4.

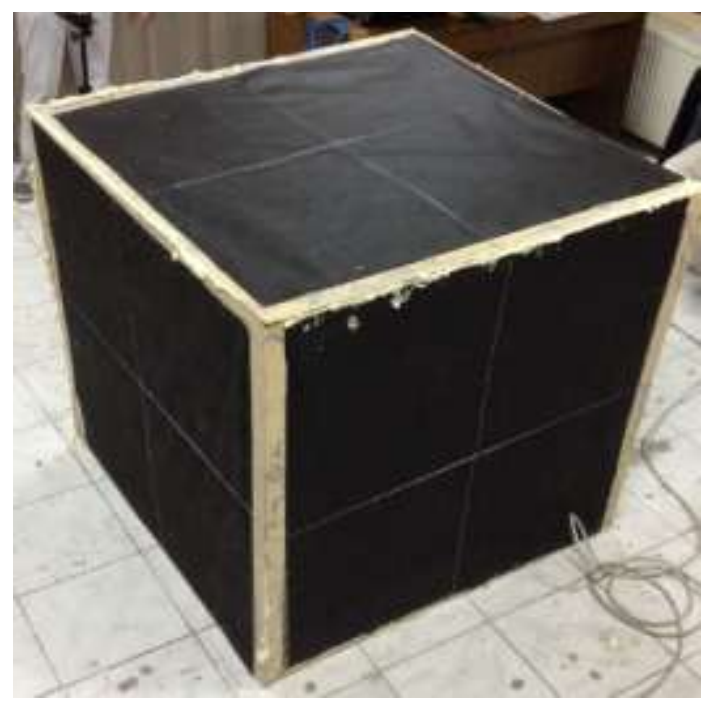

Figure 3. CelluBOR cabin

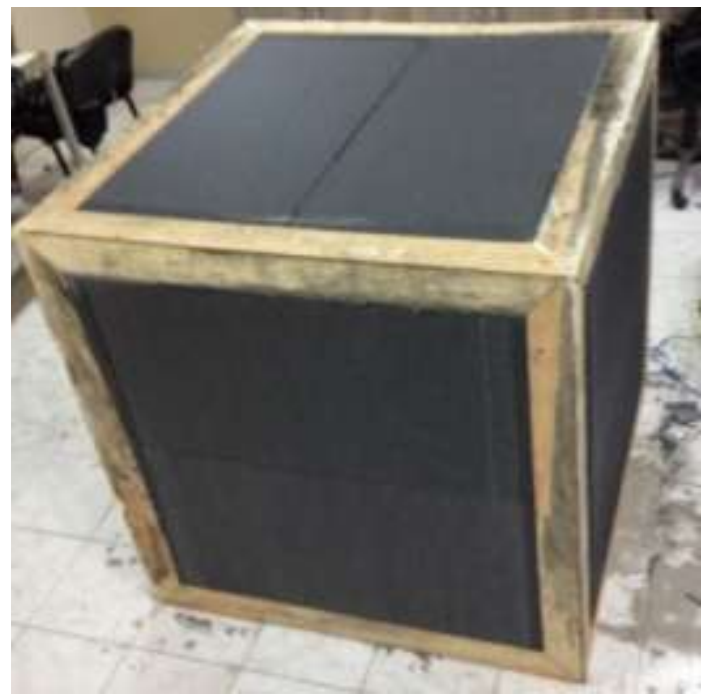

Figure 4. Styrofoam cabin

Five models were constructed for measurements and analyses, as seen in Table 1 .

The noise source, which was constituted of white noise, was placed in the middle of the cabins Fig. 5. The sound level meter used was the Bruel\&Kjaer 2250 hand-held analyser. The sound level meter was calibrated before and after all measurements.

\begin{tabular}{cccc}
\hline $\begin{array}{c}\text { Cabin } \\
\text { Model }\end{array}$ & $\begin{array}{c}\text { Wall } \\
\text { Material }\end{array}$ & $\begin{array}{c}\text { Thickness } \\
(\mathbf{c m})\end{array}$ & Designation \\
\hline 0 & No cabin & - & - \\
\hline 1 & CelluBOR & 5 & B5 \\
\hline 2 & Styrofoam & 5 & S5 \\
\hline 3 & CelluBOR & 10 & B10 \\
\hline 4 & Styrofoam & 10 & S10 \\
\hline
\end{tabular}

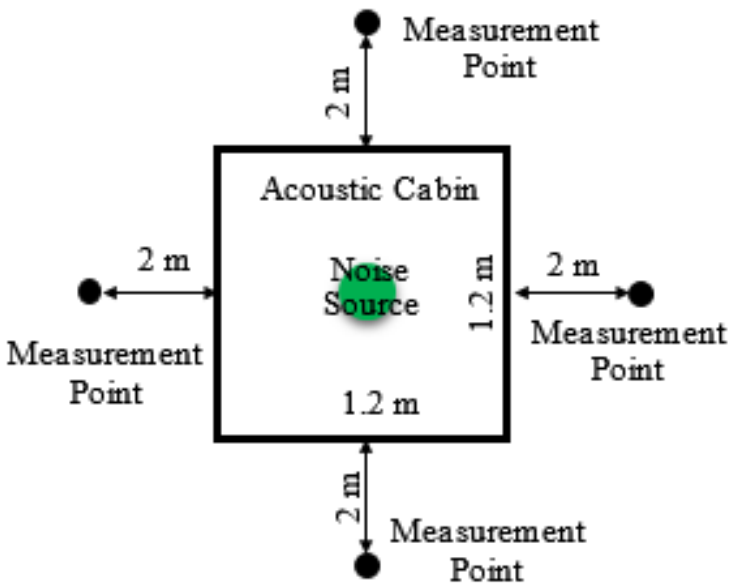

Figure 5. Measurement diagram

All measurements for the five models were conducted under the same conditions. The average values of A-weighted equivalent noise levels (LAeq), taken from four different directions, were calculated using (1).

$L A e q=10 \log \left(\frac{1}{n} \sum_{i}^{n} 10^{\text {LAeq }_{i} / 10}\right)$

Insertion loss (IL) - the most suitable parameter for demonstrating cabin performance capability - was defined by (2). LAeqO and LAeql indicate A-weighted equivalent noise levels at the same point before and after cabin capability performance test, respectively.

$$
I L=L A e q_{0}-L A e q_{1}
$$

\section{Evaluation of Measurement Results}

It was observed that the equivalent noise level of the B5 model was lower than that of S5, and similarly, that the equivalent noise level of the B10 model was lower than that of S10, as shown in Fig. 6. Since the model numbered 0 was an open model, without any cabin, it had a higher noise level. Based on Eq. 2, Fig. 7 shows that the B5 model resulted in more $9 \mathrm{dBA}$ noise reductions than the S5 model and that the B10 model resulted in more $13 \mathrm{dBA}$ noise reductions than the S10 model. 
Proc. of the Fourth Intl. Conf. Advances in Civil, Structural and Mechanical Engineering- CSM 2016 Copyright (C) Institute of Research Engineers and Doctors, USA .All rights reserved.

ISBN: 978-1-63248-093-4 doi: 10.15224/ 978-1-63248-093-4-34

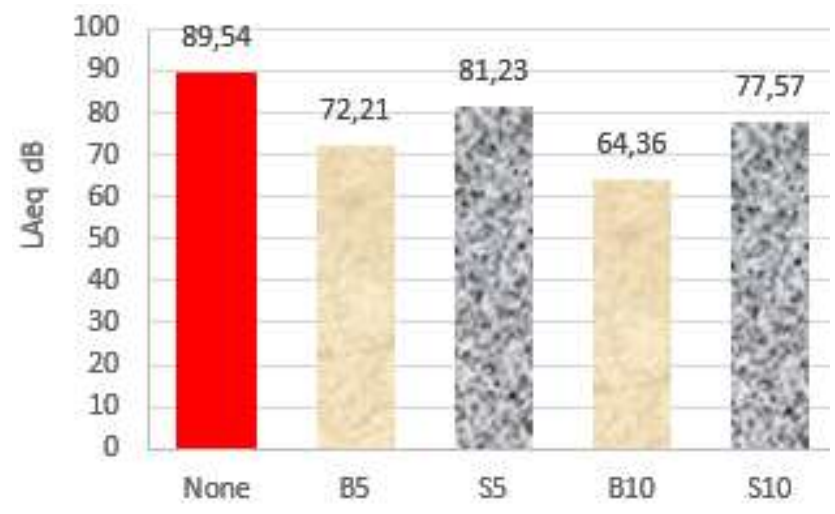

Figure 6. Equivalent noise levels

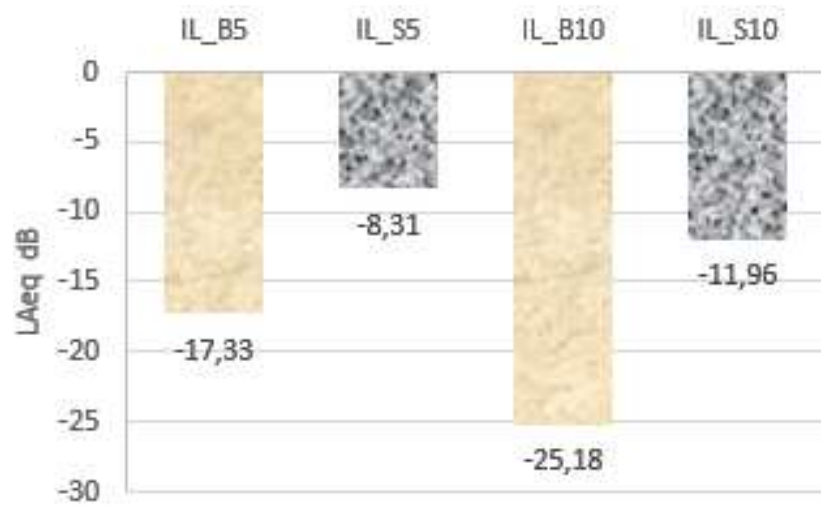

Figure 7. Insertion loss

1/1 Octave band frequency analyses of cabin models were performed. Equivalent noise levels of the B5 model at 31.5, 63 and $125 \mathrm{~Hz}$ central frequency bands were slightly higher than those of the S5 model. However, equivalent noise levels of the B5 model at 250, 500, 1000, 2000, 4000 and $8000 \mathrm{~Hz}$ central frequency bands were lower than those of the S5 model, as shown in Fig. 8. Similarly, equivalent noise levels of the B10 model at 31.5, 63 and $125 \mathrm{~Hz}$ central frequency bands were slightly higher than those of the S10 model, but lower at other frequency bands, as seen in Fig. 9.

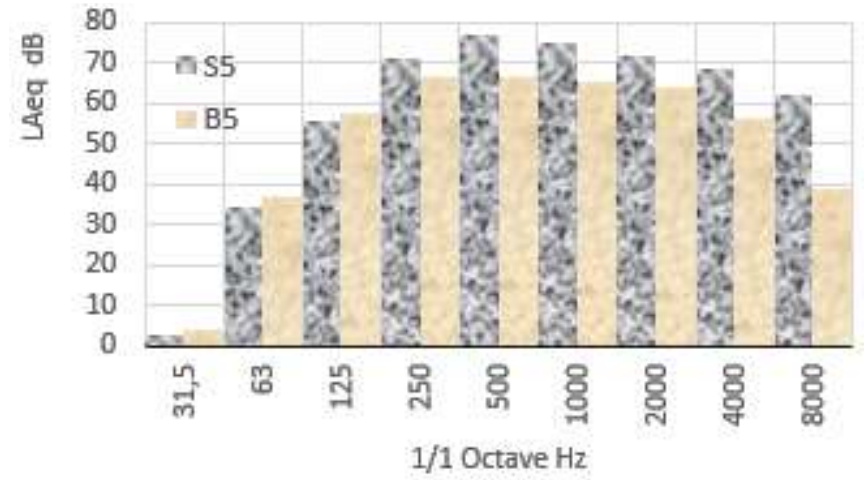

Figure 8. 1/1 Octave band analyses of S5 and B5

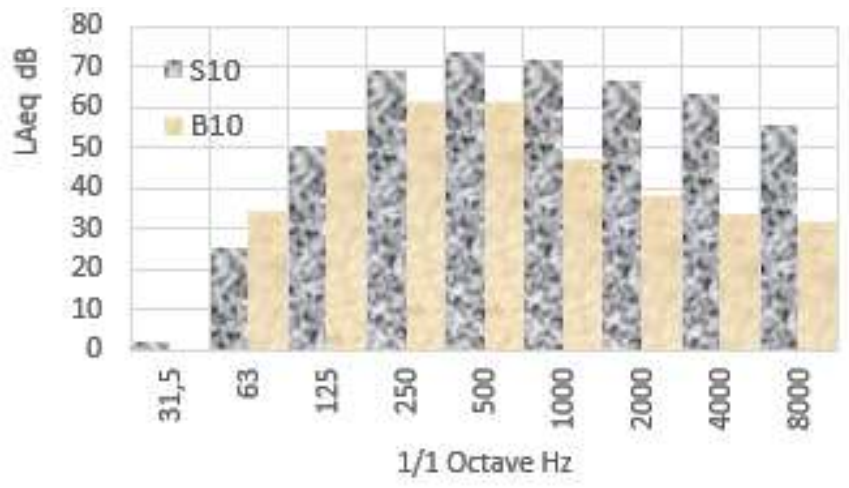

Figure 9. 1/1 Octave band analyses of S10 and B10

1/1 Octave band analyses of all models were also performed according to their wall thicknesses. The S10 model at 63 and $125 \mathrm{~Hz}$ frequency bands resulted in effective noise reduction. At frequencies above $250 \mathrm{~Hz}$, where human ears are so sensitive, no significant change was observed for equivalent noise levels of S5 and S10 models, as shown in Fig. 10. Fig. 11 indicates that the B10 model resulted in more effective noise reduction than the $\mathrm{B} 5$ model at all frequency bands.

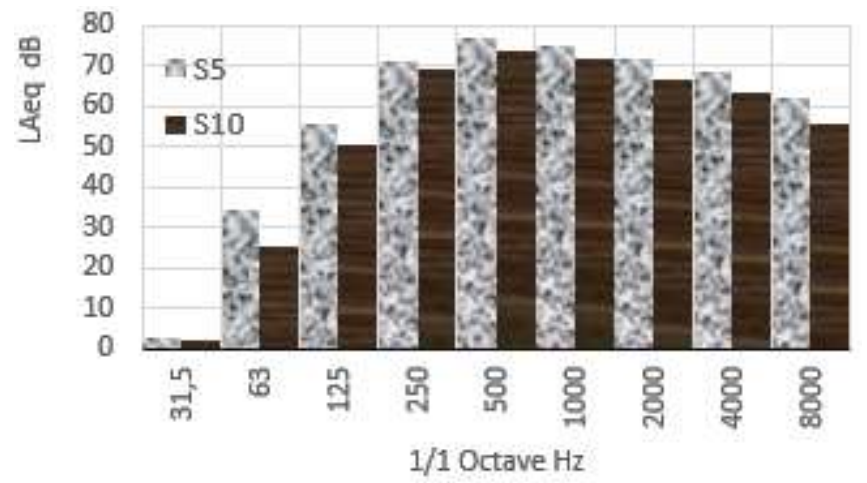

Figure 10. 1/1 Octave band analyses of S5 and S10

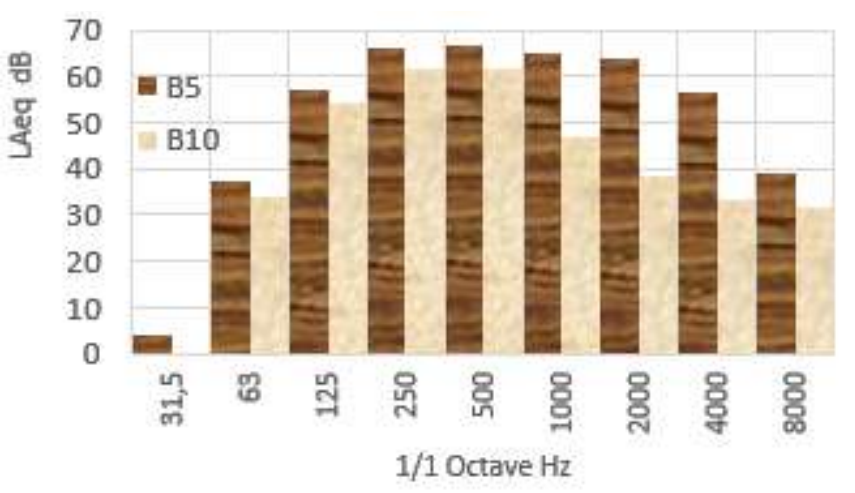

Figure 11. 1/1 Octave band analyses of B5 and B10 


\section{Conclusions}

It was observed that CelluBOR resulted in stronger and more efficient noise reduction than Styrofoam; in other words, it provided better noise insulation. Based on octave band analysis results, the noise insulation of CelluBOR was less effective at lower frequency bands, but at higher frequency bands, where human ears are so sensitive, it was considerably more efficient than Styrofoam. The effect of Styrofoam's thickness on noise insulation was slightly low, while the thickness of CelluBOR had a significant effect on the noise reduction.

\section{Acknowledgment}

This work was supported by the Research Fund of the Sakarya University (Project Number: 2014-01-06-003 and 2014-01-06-002) and by Sakarya CelluBOR BGB Yapı Ltd. Şti.

\section{References}

[1] R.L. Carroll, Compensation for occupational noise induced hearing loss in Australia and New Zealand, International Congress Series 1240 (2003) 161- 163J. Clerk Maxwell, A Treatise on Electricity and Magnetism, 3rd ed., vol. 2. Oxford: Clarendon, 1892, pp.68-73.

[2] G.H. Shaikh, Occupational noise exposure limits for developing countries, Applied Acoustics 57 (1999) 89-92.

[3] B.R., Eduardo, M. F. de Azevedo, F. João Aragão Ximenes, Study of the hearing in children born from pregnant women exposed to occupational noise: Assessment by distortion product otoacoustic emissions, Rev Bras Otorrinolaringol, 2007;73(3):359-69.

[4] C. Zhang, S. Yuan, D. Li, Comprehensive Control of the Noise Occupational Hazard in Cement Plant, Procedia Engineering 43 ( 2012 ) $186-190$.

[5] H.N. Madbuli, A.Z. Mohamed, Occupational exposure to noise and hearing thresholds among civilian aircraft maintenance workers, International Journal of Industrial Ergonomics 43 (2013) 495-502.

[6] H. Yaw-Huei, C. Han-Yueh, Y.J. Mei-Chu, W. Jung-Der, The association between low levels of lead in blood and occupational noiseinduced hearing loss in steel workers, Science of the Total Environment 408 (2009) 43-49.

[7] G. Tomei, M. Fioravanti, D. Cerratti, A. Sancini, E. Tomao, M.V. Rosati, D. Vacca, T. Palitti, M. Di Famiani, R. Giubilati, S. De Sio, F. Tomei, «Occupational exposure to noise and the cardiovascular system: A meta-analysis, Science of the Total Environment 408 (2010) 681-689.

[8] R. Pääkkönen, J. Tikkanen, A low-volume, low-frequency noise chamber, Applied Acoustics, Volume 29, Issue 2, 1990, Pages 151-165.

[9] G. Locati, A. Vicini, F. Cetta, F. Ombello, Reducing machine heat and noise by a special enclosure, Applied Ergonomics, Volume 7, Issue 2, June 1976, Pages 93-96.

[10] D. Jean-Baptiste, G. Marie-Annick, Active absorption to reduce the noise transmitted out of an enclosure, Applied Acoustics 70 (2009) 142152.

[11] Y.Y. Li, Noise control of an acoustic enclosure covered by a double-wall structure with shallow gap: Design of resonator-like cavities, Applied Acoustics 71 (2010) 675-680.

[12] T. Marco, R. Alain, Modeling of influencing parameters in active noise control on an enclosure wall, Journal of Sound and Vibration 311 (2008) 1325-1339.

[13] Y. Ganghua, C. Li, Location optimization of a long T-shaped acoustic resonator array in noise control of enclosures, Journal of Soundand Vibration328(2009) 42-56.

[14] http://www.cellubor.com/ 